\title{
Transdisciplinary Collaboration in Renewable Energy Projects - A Case Study from Mustang, Nepal
}

\author{
Martina Maria Keitsch ${ }^{1, *}$, Nyima Tsering Gurung ${ }^{2}$ \\ ${ }^{1}$ Norwegian University of Science and Technology, Trondheim, Norway \\ ${ }^{2}$ Entrepreneur, Jhong Mustang \\ Corresponding Email: martina.keitsch@ntnu.no
}

\begin{abstract}
:
In the recent years, transdisciplinary research and development have received increased attention, also in renewable energy planning and design. In contrast to theory-driven research, transdisciplinary approaches relate to the real-life phenomena and societally relevant problems. Transdisciplinary collaboration (TDC) emphasizes the mutual learning process between researchers and actors from outside academia, and the common creation of knowledge that is solution-oriented, socially robust and transferable to both scientific and societal practice. The following article discusses a transdisciplinary collaboration project on planning and designing a Solar Street Light solution in the village of Jhong, Mustang. The project is part of the MSESSD program at IOE, which has the goal to plan and implement renewable energy solution in rural areas in Nepal. The goal of the solar street light project was to contribute to Jhong's approach of becoming a sustainable settlement. The article analyses three TDC phases of the project: 1. Gather information, discuss the problem with stakeholders and translate material, functional, operational requirements into scientific researchable questions. 2. Documenting strategies to develop a mutual learning process and 3. Assessing results for both for the stakeholders and for academic practice. Findings of the project indicate that transdisciplinary collaboration in renewable energy projects can help to operationalize learning between different actors and realize applicable results on contextualized levels. However, planned outcomes may vary and from a scientific perspective, methodologies for TC are not clearly defined or systematized yet, terminologies are vague, and de facto power relations in the field can obstruct the collaboration process. The last part of the article will point out some of the future challenges and possibilities for transdisciplinary research and development.
\end{abstract}

Keywords: Transdisciplinary Collaboration, Renewable Energy Project Planning, Stakeholder Inclusion

\section{$1 \quad$ Introduction}

Transdisciplinarity (TD) is receiving increased attention in both academia and society. Transdisciplinary approaches aim to work across scientific and nonscientific stakeholder communities, relating to real-life phenomena and societally relevant problems. Main goals of transdisciplinary collaboration are facilitating a systemic way of addressing challenges, and communicatively encouraging mutual learning processes between actors. Common knowledge generated should be solution-oriented, socially robust and transferable to both scientific and societal practice [1].

Traditional roles for academia have been research and education. However, in the last decades a new role gained increased recognition - creating practical knowledge for the use of society. This may be partly due to the fact that new knowledge is increasingly generated outside universities, and concepts such as life-long learning, online learning and open source information become regular elements in academic life [2]. Additionally, concepts such as Sustainable Development and the Sustainable Development Goals (SDGs) require combined efforts to meet today's challenges [3] and the co-production of knowledge between academic and nonacademic actors might contribute to 'join forces'. The following article discusses a transdisciplinary collaboration project on planning and designing a Solar Street Light solution in the village of Jhong, Mustang. The project is part of the MSESSD program at IOE, which has the goal to plan and implement renewable energy solution in rural areas in Nepal. The goal of the solar street light project was to contribute to Jhong's approach of becoming a sustainable settlement. The article analyses three TC phases of the project: 1. Gather information, discuss the problem with stakeholders and translate material, functional, operational requirements into scientific researchable questions. 2. Documenting strategies to develop a mutual learning process and 3 . Assessing results for both for the stakeholders and for academic practice. Findings of the project indicate that transdisciplinary collaboration in renewable energy projects can help to 


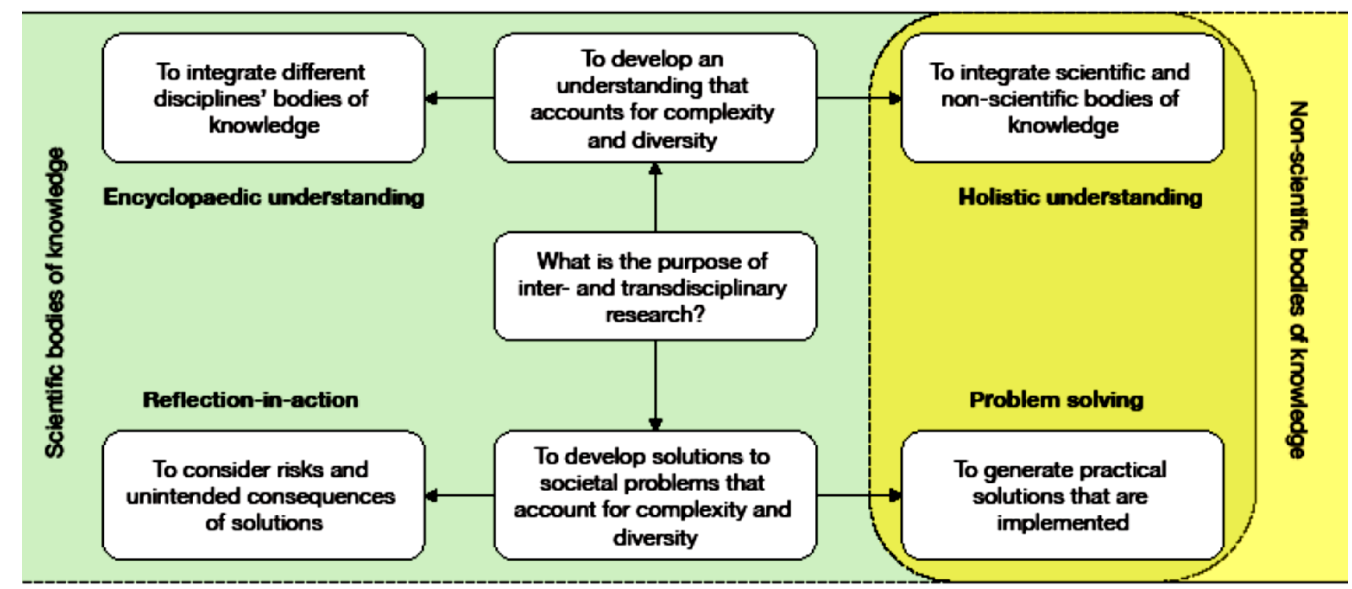

Figure 1: TDC goals, Source: Swiss Academies of Science [8]

operationalize learning between different actors and realize applicable results on contextualized levels. However, planned outcomes may vary and from a scientific perspective, methodologies for $\mathrm{TC}$ are not clearly defined or systematized yet, terminologies are vague, and de facto power relations in the field can obstruct the collaboration process. The last part of the article will point out some of the future challenges and possibilities for transdisciplinary research and development.

\section{Transdisciplinary collaboration}

\subsection{Theory approaches}

Transdisciplinarity provides an alternative to disciplinary knowledge generation. The concept has been discussed since the early 1970, but is still ambiguous, and as a term interpreted and used in multiple ways. General epistemological characteristics of transdisciplinarity are at least threefold [4]: 1) addressing the complexity of science and 'knowledge fragmentation' and integrating theoretical ('disciplinary') and practical (professional and laypeople) knowledge, 2) including local contexts and uncertainty, and 3) applying communicative interaction and collaboration during in all phases. The sustainable development concept corresponds with the transdisciplinary movement as well [5], for example, R\&D on the Sustainable Development Goals (SDGs) and TDC is often intertwined [6]

Transdisciplinary goals ascribed are manifold. Some authors paradigmatically claim the goal of transdisciplinarity as creating engaged, socially responsible science, while others specify goals more detailed according to certain conditions and tasks [7]. Generally, the following goals of TD can be identified within a planning, design and development process.
TDC approaches in planning and design have existed since some decades and applying stakeholder inclusion methods such as interviews, observation, focus groups and workshops are common. The novelty of the TDC described and analyzed in the next chapters is however that the researchers and local stakeholders kept collaborative and communicative activities throughout the whole process from identification of issue, planning of solution, identifying physical, functional and organizational requirements, designing a prototype and implementing the solution [9]. Both the researchers .and key stakeholders did the evaluation phase three month after project accomplishment. Ideally, a new evaluation should be done three years after the project. The following subchapter describes the TDC on solar streetlight in Jhong, Mustang.

\subsection{TDC in practice: Planning and designing a Solar Street Light solution}

Jhong VDC lies in the north part of the Himalaya region of Nepal at $3540 \mathrm{~m}$ height altitude. It is located in Lower Mustang and next to the Muktinath holy temple. Administratively, Jhong as ward 2 comprises two other villages; Chhoekhor and Putak. This is the former Jhong VDC. It comprises total 95 households. The major ethnic group is Gurung with $84.19 \%$ of total population. Jhong ward has total residents of 253,112 men and 141 women [10]. The Jhong people follow their own cultural, historical, and religious traditions from many centuries ago. They have their traditional festival, language and food habits. People in Jhong follow Shakya Buddhism and many sacred practises like doing puja and preying are part of their daily life. There are many prayers and strong beliefs in gods and goddesses to prevail peace and prosperity in the house or village. Generally, nature and humans are seen as 
dependent on each other. Jhong people mostly honour nature by law and respect, despite the use of modern technology. Mountains are the greatest wealth of Mustang; they are regarded as are ornaments and representations of the divine. Mountains are also the greatest water resources for household and irrigation purposes.

The land topography of Jhong village is slope. Most of the land area is barren and covered with low vegetation. Jhong village has a motorable road. Although near to the Muktinath holy temple and spectacular mountain scenarios, few pilgrims and tourists visit the village. The lack of facilities like hotels, lighting, and internets are the reasons of not developing as a tourist hub. The main occupation of the Mustang people remains agriculture as subsistence farming whereas wheat, barley, grains and buckwheat are mostly cultivated products. Apple and potato are main source of income from agriculture, and recently motivated apple farming and plantation provides local income generation. Some local people also engage in tourism business, like hotels, restaurants and trekking agencies in recent years. People are bound to keep different animals for foods and farming. They use horses for transportation, trades, and other animals for meat and compost for fertilizer. Rare and costly herbs like Yarchagumba are another source of income for the locals.

The active involvement of stakeholders has gained an increasing importance for many project activities in recent years, for example under the 'Local Government and Community Development Programme' (LGCDP). The Community Development Programme (CDP) is connected to the LGCDP, and implemented by the Ministry of Federal Affairs and Local Development (MoFALD) and local municipalities. From 2015 to 2017, the CDP supported governance for better local service delivery in 18 districts. It strengthens development of local governance institutions such as Citizen Awareness Centres (CACs), Ward Citizen Forums (WCFs), and Integrated Plan Formulation Committees (IPFCs). The CDP support is based on the 14-step planning process [11].

Besides political conditions and regulations, overall project goals and expected results in a transdisciplinary project should be approved by all relevant stakeholders locally and to some extend regionally in order to achieve and implement successful solutions [1]. This has been attempted in this project with a special focus on local stakeholders.
Inclusion of stakeholders in every project phase like planning stage, design stage, implementation stage, operation and maintenance stage is also necessary for the sustainability of the project. Discussions on stakeholders' views, opinions and ideas can take place through meetings, workshops and interviews. Currently there are several projects, which are self-sustained and carefully maintained by the local people in the Jhong ward, the former Jhong VDC. For example, the public mill and the public toilets in Putak, community plantations in Jhong, and irrigation in Chhoekhor village. These small, partly governmental funded projects are essential for the locals. They take place on a local level and are successful because local stakeholders know their needs and challenges, and share the responsibility to take care of the public property. Initiatives started and maintained by local stakeholders are necessary not only for the success of project but also because they imply indirect benefits to locals and encourage village innovation.

The assurance of stakeholder inclusion, cooperation between local stakeholders and professionals along with the demarcated role of the trained locals is crucial for making a project successful. Training of the local people to operate and maintain will provide them with ideas and confidence required. Training documents have be design appropriately of example with help of visualization and clear technical instructions. The clarification of issues around major public areas like Gumpa, Health Post, Youth Club, Ama-Samuha, school buildings, community buildings etc. or topics as water, energy or waste management, has ideally to be identified before the commencement of the project in coordination with the villagers in workshops and meetings. Mass training, operation and maintenance responsibility can be given according to abilities and interests to enhance overall local participation welfare.

This article defines 'internal stakeholders' as locals in specific areas or villages, who are directly affected by the projects planning and outcomes. 'External stakeholders are actors whose decisions and strategies have affected or are affecting the locals. Governmental and non-governmental organisations are sometimes present as external stakeholders, involved in community development activities in Mustang. These external stakeholders play a vital role in the local development, but their contributions and efforts may result in both, positive and negative effects on the local atmosphere. Most of the government projects are largely relating to the infrastructure development in 
villages, like community buildings, toilets, irrigation system, drinking water projects etc., whereas community-based governmental or non-governmental activities are largely engaged in social, animal health and agricultural development. Usually small grant projects are handed to the locals for implementation. Governmental projects are more effective, but they have often a short-term vision and must meet certain criteria to be fulfilled within a limited period.

Thus, some project fails because of short duration on implementation, lack of strategy, unfavourable weather conditions and some internal local disagreements. There are many community-based GOs and NGOs like agriculture development office, animal service office, District coordinate committee etc. Further, WCF, CAC, ward office and so on. Among these government services are private providers, who are engaged in the infrastructure development and social development in the villages. There are also many non-governmental organizations, which are actively contributing to the local development in Mustang.

In terms of energy, approximately more than $80 \%$ of locals in Mustang still rely on wood, cow dunk, coal, charcoal, rarely on LPG and kerosene. Firewood and cow dunk are used for cooking and heating purposes, they are locally available resources at low cost. However, collecting cow dung and firewood is extremely time consuming and physical exhausting work for the people. Relying on such energy sources for heating and cooking can also affect the health of local people directly or indirectly and contribute to increase environmental degradation and a high national poverty level.

The energy situation in Mustang is critical at present. There are however plenty of locally available resources, which can be introduced and utilized with proper installation and management in order to meet the governmental policy of poverty reduction and assurance of health of local people.

A report from World Bank stated that Mustang has a maximum of solar and wind energy resources in Nepal. Map. Red coloured areas in the figure below represent high solar and wind energy. Recently solar energy has also been introduced for cooking and lightning purposes as in the project described below.

It is very important to properly utilize renewable energy to achieve a healthy environment and sustainable development in Mustang. Planning and implementing renewable energy solutions implies also costs for labour and maintenance. Therefore, the economic parts of renewable energy project development are equally important to analyse in all stages.

The par-capita income of Mustang is approximately 1,922 USD annual in 2014. The Western Mountain districts of Mustang have a demographic and economic profile relatively small populations, higher levels of migration, remittance income and the impact of tourism. The infrastructure development of this area is partly financed or supported by the local government and community-based organizations. More than 20\% contributions and the implementing process is taken care of by local stakeholders in most of the

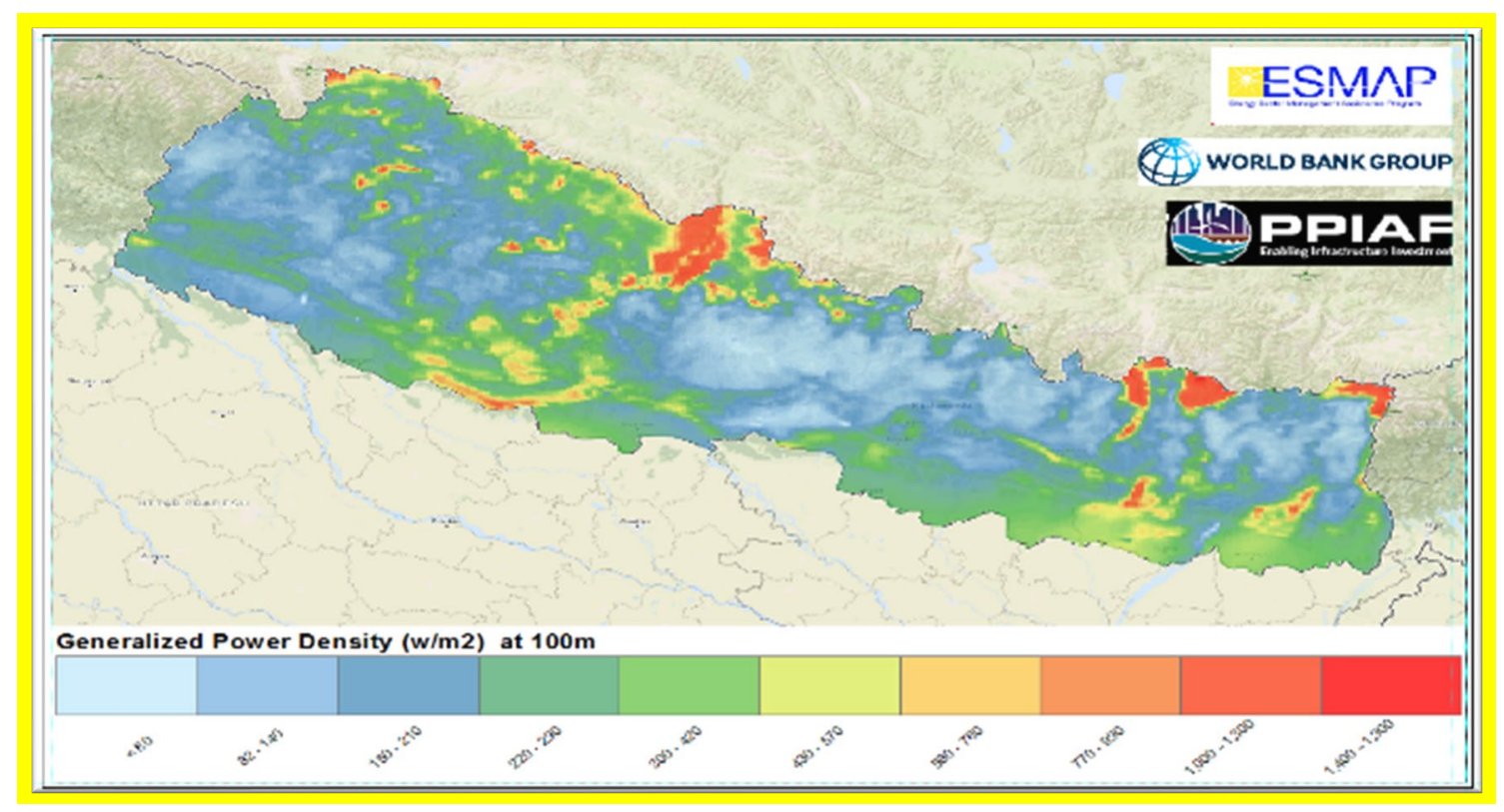

Figure 2: World Bank Map on Solar Energy in Nepal 
infrastructure development projects in Mustang. Usually consumer committees are formed after the project for implementations. There are some governmental committees appointed for specific functioning like agriculture development, animal welfare, drinking water committee etc. in the village. On the other side, undertaking committees for each project are selected by the villagers under the leadership of Gaun mukhya, comprising members for the committee, maintenance committee, supervise committee etc.

The solar project from MSESSD started in spring 2015. In a village meeting, the locals opted for a solar street light project because of three reasons: 1 . Jhong Village has access to the national grid but due to extreme weather conditions, and the grid fails frequently. 2. There is sufficient solar energy to produce solar light, the sun shines up to $12 \mathrm{hrs}$ a day yearly. Once a solar power solution is established power cuts can be met without difficulties. 3. An SSL benefits not only the local people but it encourages other villages as well and promotes sustainability.

In autumn 2015, a group of MSESSD students went to Jhong to conduct observations and interviews. The students also conducted in a workshop with 19 participants, including village leaders and political party representatives. They used a funneling approach, illustrated in Figure 1 to specify technical, functional and operational requirements and drafted the following solution (Figure 3) of which a slightly simplified version was manufactured.

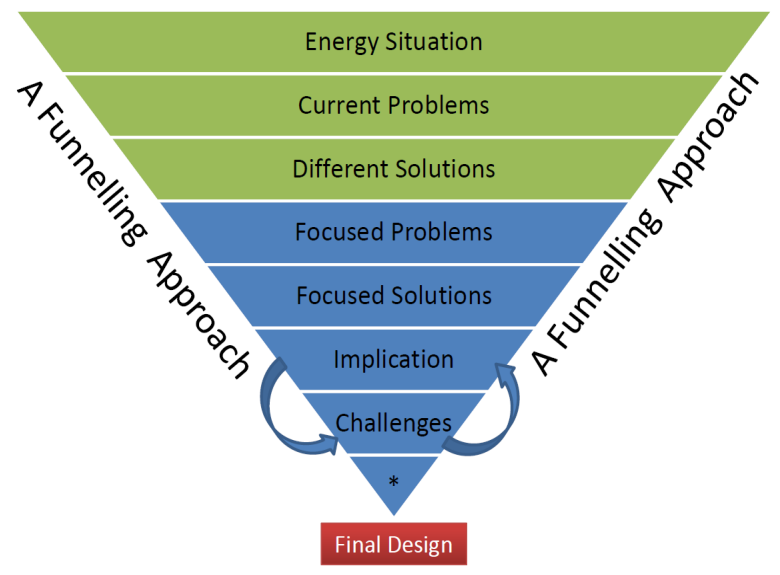

Figure 3: Funneling approach in Stakeholder workshop

Conclusively, a greater number, the installation of several SSLs needs a proper planning, financing and maintenance scheme. An energy committee has to be formed in the village and a detailed cost-benefit analysis to be done to see how many SSLs are feasible (the student group did an approximate CBA). Preparation of brochures and pamphlets indicating the working principle, operation manual, maintenance schedule and other relevant information should be provided to the locals.

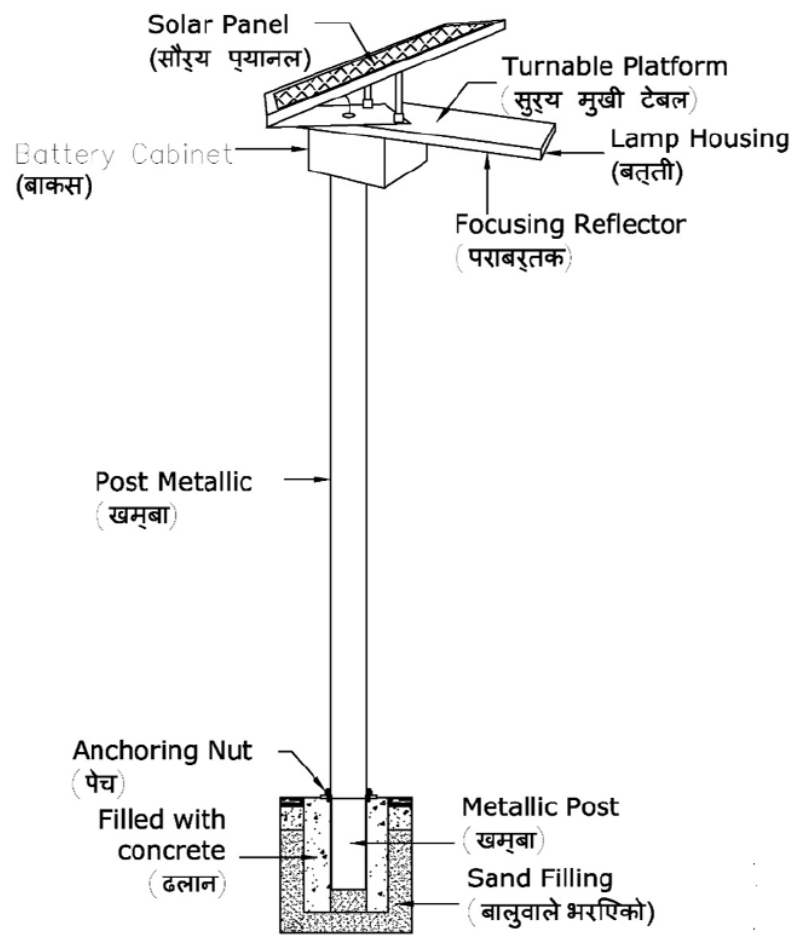

Figure 4: Solar Street Light for Jhong village

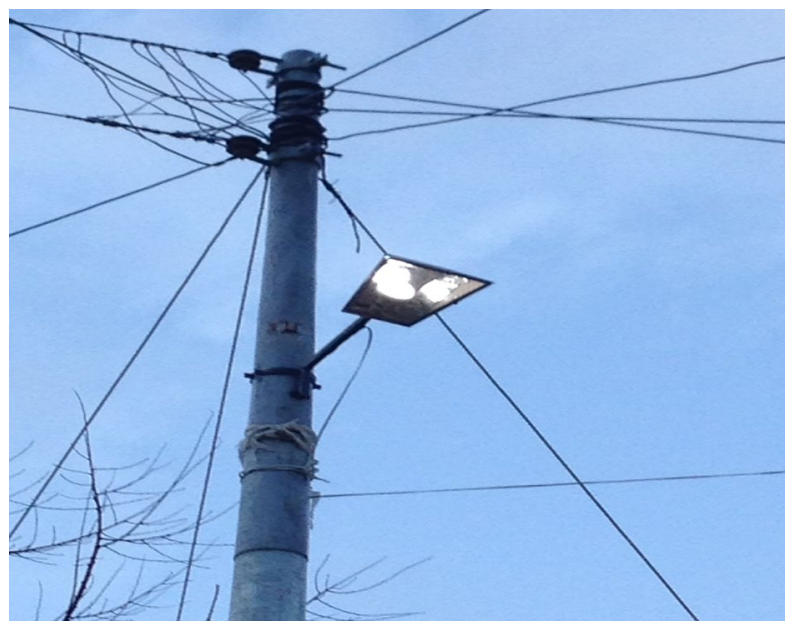

Figure 5: Solar Street Light prototype

Dissemination is also vital in convincing donors and governmental and their allied agencies to support the project. In July 2016 the Jhong village secretary applied to the Alternative Energy Promotion Centre for support to establish SSLs but got no financial support due to many local applications and prioritizing. So, even if the prototype was successful and manageable, SSLs were not established in Jhong due to the lack of financial means. 
However, a great spin-off of the project was that the Jhong Youth Club manufactured conventional streets lights themselves and contacted Nepal Electric Authority, which agreed to install them on poles. In this way, electric streetlights are provided to the village when the grid works.

\section{TDC analysis}

TDC elements are analyzed in this project regarding information generated, the mutual learning process, mediation of strategies and related to outcomes. In terms of values, the project comprised two objectives: (a) ensuring that communication and trust was established and maintained and (b) creating opportunities for realizing the selected solution.

In the case of Jhong, internal and external stakeholders' views, opinions and ideas were collected through meetings, semi-structured individual interviews and focus group interviews. The decision on the project 'solar street light for roads and in public places' was commonly made relating to the demand of the local inhabitants. The needs of the people, nature and type of the project were commonly identified. Trust was established through repeated meetings and collaboration activities. Further, for trust building, interviews with the local people without directly going to the topic of the project were made by the first author and a student group. TDC sometimes requires to be able to let go of the interview script and engage in authentic dialogues.

Together with the goodwill of the local stakeholders to go for the project, these activities contributed to generate mutual openness and helped to get and process in-depth information. Trust is long term a value that takes time to be established, it can increase as well as drop over a project period. Patience with each other and mutual respect for diverse views and cultural attitudes [13] are as important conditions for trust building, as acknowledging each other's expertise and professionalism. Additionally, expertise from both sides has to be made accessible e.g. with help of visualization and new media (for example serious gaming).

Regarding outcomes promoting the project e.g. as prioritizing solar street light on a higher decisionmaking level in the VDC to get the fiscal year budget, both internal and external stakeholders play a major role while researchers are less important. Generally, realizing a project on a bigger scale is a tedious process, which should be analyzed carefully before project start. The project should be integrated in an overall sustainability context rather than seen as incremental improvement. For example, contributing to eco-village development in Jhong, the eco-village concept has to be made accessible to stakeholders in a feasible in a step by step manner and based on their own decisionmaking practices [14].

\section{Conclusion}

Transdisciplinary work changes how disciplines at universities work by actively including civil society and societal stakeholders. Its focus is on addressing complex, challenging situations that cannot be solved from just one sectoral perspective [15]. For academia, TDC has many benefits and challenges. Learning processes have to be developed to create common understanding for example with help of visualization and creative methods that include different knowledge and experience levels. Researchers should reflect on their role and responsibilities more deeply within in a dynamic and contextual setting. The results of TDC project and process should be disseminated to relevant audiences, who in turn have to promote and apply them, while channels of information and knowledge dissemination may vary in form and type [16]. Dissemination can also happen, when the former partners start working on different problems in the same context, reapplying practices that worked before and learning from former experiences and challenges [14]. In this way, the resultant transdisciplinary knowledge can be kept alive and dynamic, because those co-creating it are active and alert on dealing with new and comprehensive local sustainability opportunities. In case of Jhong this means how to adapt and adjust ecovillage strategies and embed for example solar- and renewable energy use, waste, and water management and income generation into the overall picture of a resilient, sustainable village.

\section{Acknowledgments}

"The authors are thankful to the people of Jhong, Chhoekhor and Putak and to the MSESSD student group 1 course CC5, Batch 2."

\section{References}

[1] Hirsch, G. \& Hoffmann-Riem, H. (Eds.). Handbook of Transdisciplinary Research, Springer Publisher 2008. 
[2] Bergmann, M. Methods for Transdisciplinary Research: A Primer for Practice, Campus 2013

[3] Huutoniemi, K. \& Tapio, P. (Eds.). Transdisciplinary Sustainability Studies: A Heuristic Approach. Routledge Publisher 2014.

[4] Lawrence, R. J. (2010). Beyond Disciplinary Confinement to Imaginative Transdisciplinarity. In V. A. Brown, J. A.

[5] Hirsch \& Hadorn, G., (2008). The Emergence of Transdisciplinarity as a Form of Research. In Hirsch, G.,

[6] Evans, J. P., (2012): Environmental Governance. London, UK: Routledge.

[7] Hall, et.al (2012) A Four-Phase Model of Transdisciplinary Team-Based Research: Goals, Team Processes, and Strategies. Accessible online, accessed 24.8.2018 https://www.ncbi.nlm.nih.gov/pubmed/23483588).

[8] TDC goals, Source: Swiss Academies of Science, td-net. http://www.transdisciplinarity.ch/tdnet/Transdisziplinarita et/Forschungszwecke.htmlB

[9] Leavy, P. Essentials of Transdisciplinary Research: Using Problem-Centered Methodologies. Routledge Publisher 2011.

[10] National Population and Housing Census 2011, 2014.

[11] Local Government and Community Development Programme. http://lgcdp.gov.np/

[12] World Bank (2017) Solar Resource and Photovoltaic Potential of Nepal.

http://documents.worldbank.org/curated/en/585921519 658176633/pdf/123705-ESM-P150328-PUBLICNepalSolarMappingCountrySolarResourceReportMarc h.pdf

[13] Dinca., I. (2011). Stages in the configuration of the transdisciplinary project of Basarab Nicolescu. In B. Nicolescu (Ed.), Transdisciplinary studies: Science, spirituality and society (No. 2) (pp. 119-136). Bucharest, Romania: Curtea Veche Publishing House. Retrieved from http://basarab-nicolescu.fr/Docs_Notice/Irina_Dinca.pdf

[14] Keitsch. M, Gurung N. (2018) Stakeholder Collaboration in Rural Settings. Part 1: Manual for Local Project Planning, in print.

[15] McGregor, S. L. T. (20 1 5). Transdisciplinary knowledge creation. In P. T. Gibbs (Ed.), Transdisciplinary professional learning and practice (pp. 9-24). New York, NY: Springer.

[16] Defila, R., \& Di Giulio. (2015). Integrating knowledge: Challenges raised by the 'inventory of synthesis.' Futures, 65(1), 123- 135 . 